\title{
Passive tobacco exposure may impair symptomatic improvement in patients with chronic angina undergoing enhanced external counterpulsation
}

\author{
Stilianos Efstratiadis ${ }^{1}$, Elizabeth D Kennard ${ }^{2}$, Sheryl F Kelsey², \\ Andrew D Michaels*1 for the International EECP Patient Registry-2 \\ Investigators
}

Address: ${ }^{1}$ Department of Medicine, Division of Cardiology, University of Utah, Salt Lake City, Utah, USA and ${ }^{2}$ Department of Epidemiology, University of Pittsburgh, Pittsburgh, Pennsylvania, USA

Email: Stilianos Efstratiadis - stilianos.efstratiadis@hsc.utah.edu; Elizabeth D Kennard - kennard@edc.pitt.edu;

Sheryl F Kelsey - kelsey@edc.pitt.edu; Andrew D Michaels* - andrew.michaels@hsc.utah.edu; the International EECP Patient Registry-2 Investigators - kennard@edc.pitt.edu

* Corresponding author

Published: 17 September 2008

BMC Cardiovascular Disorders 2008, 8:23 doi:10.1 186/147I-226I-8-23

This article is available from: http://www.biomedcentral.com/|47|-226I/8/23

(c) 2008 Efstratiadis et al; licensee BioMed Central Ltd.

This is an Open Access article distributed under the terms of the Creative Commons Attribution License (http://creativecommons.org/licenses/by/2.0), which permits unrestricted use, distribution, and reproduction in any medium, provided the original work is properly cited.
Received: 3 August 2007

Accepted: 17 September 2008

\begin{abstract}
Background: The adverse effects of tobacco abuse on cardiovascular outcomes are well-known. However, the impact of passive smoke exposure on angina status and therapeutic response is less well-established. We examined the impact of second-hand smoke (SHS) exposure on symptomatic improvement in patients with chronic ischemic coronary disease undergoing enhanced external counterpulsation (EECP).

Methods: This observational study included I,026 non-smokers (108 exposed and 918 notexposed to SHS) from the Second International EECP Patient Registry. We also assessed angina response in 363 current smokers. Patient demographics, symptomatic improvement and quality of life assessment were determined by self-report prior and after EECP treatment.

Results: Non-smoking SHS subjects had a lower prevalence of prior revascularization (85\% vs $90 \%)$, and had an increased prevalence of stroke (I3\% vs $7 \%$ ) and prior smoking ( $72 \%$ vs $61 \%$; all p $<0.05$ ) compared to non-smokers without SHS exposure. Despite comparable degrees of coronary disease, baseline angina class, medical regimens and side effects during EECP, fewer SHS non-smokers completed a full 35 -hour treatment course $(77 \%$ vs $85 \%, \mathrm{p}=0.020)$ compared to non-smokers without SHS. Compared to non-smokers without SHS, non-smoking SHS subjects had less angina relief after EECP (angina class decreased $\geq$ I class: $68 \%$ vs $79 \% ; p=0.0082$ ), both higher than that achieved in current smokers (66\%). By multivariable logistic regression, SHS exposure was an independent predictor of failure to symptomatic improvement after EECP among non-smokers (OR I.8I, 95\% confidence intervals I.16-2.83).
\end{abstract}

Conclusion: Non-smokers with SHS exposure had an attenuated improvement in anginal symptoms compared to those without SHS following EECP. 


\section{Background}

Epidemiological evidence has unequivocally confirmed that active smoking is a risk factor for cardiovascular disease and the leading cause of preventable death $[1,2]$. The impact of passive smoking on the cardiovascular system was recognized nearly two decades ago, when evidence of the harmful effects of second-hand smoke (SHS) began to emerge $[3,4]$. In the past decade, clinical data from the Atherosclerosis Risk in Communities (ARIC) studies demonstrated that both active and passive smoking were associated with accelerated atherosclerosis progression [5]. Steenland et al reported that the risk of death due to cardiovascular disease (CVD) increases by $30 \%$ in nonsmokers who live together with smokers [6]. Another study suggested that in the United States more than 50,000 deaths annually from ischemic heart disease are associated with SHS [7]. Epidemiological data suggest a non-linear dose-response relationship between the intensity of exposure to SHS and the risk of ischemic heart disease $[8,9]$. The excess risk of developing CVD amounts to $80 \%$ in active smokers at the age of 65 , but it may also be as high as $30 \%$ in passive smokers [10]. Using measurements of the serum concentration of cotinine, a biomarker of smoke exposure, in a large prospective population study, Whincup et al recently concluded that the risk of coronary heart disease related to passive smoke exposure has probably been underestimated in earlier reports and might, in fact, be very close to the risk reported for active smokers [11].

Enhanced external counterpulsation (EECP) is a noninvasive treatment for chronic, refractory angina that involves the sequential inflation of three sets of lowerextremity cuffs during diastole, leading to increased venous return and cardiac output, systolic unloading, and augmentation of the coronary artery perfusion pressure. EECP has been shown to be effective in treating patients with chronic ischemic coronary artery disease using various measures, including improved functional class [12], reduced anginal symptoms [13], improved quality-of-life indices $[14,15]$, improved stress cardionuclide perfusion $[16,17]$, increased exercise time $[18,19]$, and increased time to ST-segment depression [20]. Treatment with EECP has also been demonstrated to increase nitric oxide levels and decrease malondialdehyde, a marker of lipid peroxidation, as well as to decrease endothelin-1 levels. Moreover, the benefit of EECP has been shown to be sustained at 3 - and 5-years after treatment by radionuclide stress testing and quality-of-life measures $[21,22]$.

There have been several emerging predictors of a lower likehood of benefit from EECP treatment including the presence of diabetes mellitus, prior surgical coronary revascularization and heart failure [23]. Moreover, nonsmoking patients undergoing EECP treatment had clearly improved symptom reduction compared to current smokers [23]. We examined the impact of second-hand smoke (SHS) exposure on angina status in patients with refractory angina undergoing EECP treatment.

\section{Methods}

The study group consisted of 1,026 non-smoking and 363 current smoking patients treated with EECP for refractory angina enrolled in the Second International EECP Patient Registry (IEPR-II). All patients signed informed written consent prior to entry into the Registry, and the Registry was approved by each center's institutional review board. The primary analyses were performed comparing the nonsmokers without SHS exposure $(n=918)$ and non-smokers with SHS exposure $(n=108)$. The IEPR-II enrolled consecutive patients treated with EECP for chronic angina in 73 US centers between 2002 and 2004. Briefly, the IEPR-II collected patient demographics, medical history, and coronary artery disease status before and after initiation of EECP therapy. Data were collected prospectively on anginal status according to the Canadian Cardiovascular Society Classification (CCSC), anti-anginal medication use, quality of life and adverse clinical events. The present analysis includes patients who were enrolled from sites reporting $\geq 85 \%$ clinical follow-up. Since the IEPR aimed to collect data on as broad a range of patients as possible, the criteria for entry were only that the patient gave informed consent and had at least one hour of EECP treatment for chronic angina. The patients were interviewed by telephone 6 months after the last EECP treatment session, and yearly thereafter in order to record anginal status, quality of life, and adverse cardiac events [24]. Non-smoking is defined as no current tobacco smoking, by selfreport. SHS exposure was defined as any exposure to a smoker living in the subject's household.

\section{Statistical analysis}

Data are presented as percentages for categorical variables or as mean values and standard deviations for continuous variables. Percentages and means are for patients with that data item recorded. Data were missing for fewer than 3\% of each variable collected. Comparison of continuous variables between groups was analyzed by Wilcoxon rank tests and for categorical variables by chi-square, Fisher's exact test or Mantel-Henzel tests, as appropriate. Multivariable logistic regression analysis was used to determine independent predictors of failure to achieve reduction in angina. All baseline variables associated with the outcome with a p-value of $<0.2$ were entered into the preliminary model. A backward selection procedure was used to determine independent, statistically significant predictors. Two-tailed p-values $<0.05$ were defined as significant. 


\section{Results}

Of the 1,026 non-smoking patients who underwent EECP treatment for angina, $108(10.5 \%)$ reported current SHS exposure. Demographic and clinical characteristics, such as the prevalence of hypertension, diabetes, prior myocardial infarction, heart failure, and anginal class, were similar among the two groups of non-smokers (Table 1). There was a slight trend toward more women in the SHS group $(47 \%)$ compared to the non-SHS non-smokers $(26 \% ; p=0.74)$. The SHS subjects had a lower mean age ( $66 \pm 13$ vs $68 \pm 11$ years, $\mathrm{p}=0.033$ ), with a lower proportion of patients older than 65 years old ( $53 \%$ vs $63 \%$; $p=$ $0.039)$. SHS subjects had a higher percentage of previous smoking and prior stroke, but had less reported hyperlipidemia. There was no difference in baseline angina severity between those with and without SHS exposure (Table 2).

More patients without SHS exposure finished the recommended course of at least 35 hours of treatment (85.4\% vs. $76.9 \%, p=0.020)$. The rate of major adverse cardiovascular events (myocardial infarction, coronary artery bypass graft surgery [CABG], percutaneous coronary intervention, death) during the course of EECP therapy was $5.6 \%$ for the SHS group, compared to $2.8 \%$ for the nonSHS group $(\mathrm{p}=0.12)$. However, there was a higher incidence of unstable angina during EECP in the SHS group $(8.3 \%)$ compared to the non-SHS non-smoker group $(2.6 \% ; p=0.0014)$. Other adverse events occurring during the EECP treatment period occurred at a similar rate (Table 3).

After completion of EECP therapy, angina decreased by $\geq$ 1 class in $68 \%$ of the SHS non-smoker group, compared to $79 \%$ of the non-SHS non-smoker group ( $p=0.0082$ ) both higher than the $66 \%$ angina reduction achieved by the current smoking group (Figure 1). Eleven percent of the SHS non-smoker group remained in class IV angina after EECP, compared to only $5 \%$ in the non-SHS nonsmoker group $(\mathrm{p}=0.014)$. Medical therapy, including beta-blocker, calcium channel blocker, angiotension-converting enzyme inhibitor, angiotensin receptor blocker, antiplatelet, diuretic and hypolipidemic medications, remained similar after EECP in both non-smoking groups.

A multivariable logistic regression model showed the only independent significant predictors of failure to achieve angina reduction were: SHS exposure (odds ratio 1.81, $95 \%$ confidence interval $1.16-2.83$ ), age $\leq 55$ years (odds ratio $2.10,95 \%$ CI 1.41-3.13), and mild angina (CCSC I/ II) pre-EECP (odds ratio 2.70, 95\% CI $1.64-4.46$ ).

\section{Discussion}

In this large cohort of patients with refractory angina undergoing EECP, SHS exposure was an independent predictor of failure to achieve a reduction in angina class after treatment among non-smokers. Only $68 \%$ of those nonsmoking subjects with SHS had a reduction in angina class, compared to $79 \%$ of the non-smokers without SHS exposure. This low level of angina reduction is comparable to that achieved among current cigarette smokers $(66 \%)$. Moreover, the SHS group had a higher rate of adverse unstable angina cardiac events during the course of EECP compared to non-smokers without SHS exposure.

Prior clinical studies observed impaired endotheliumdependent vasorelaxation, the earliest sign of endothelial dysfunction, in smokers [25-27]. Passive smokers, defined as those with SHS exposure, exhibited abnormal endothelium-dependent vasodilatation to a similar extent as that seen with current smokers [28]. Sumida et al found that passive smoking changes acetylcholine-induced coronary artery relaxation into vasoconstriction [29]. In another study, coronary flow reserve, although higher in nonsmokers than in active smokers under control conditions, was similar in the two groups after a 30-minute exposure to SHS [30]. These findings indicate that the relatively low doses of toxins inhaled by passive smoking are sufficient to elicit a strong acute response. It is noteworthy that the effects of SHS are acute and substantial, nearly as large compared to chronic active smoking (averaging between $80 \%$ and $90 \%$ ) [31].

Table I: Baseline Demographics and Clinical Characteristics of Non-Smokers Undergoing Enhanced External Counterpulsation

\begin{tabular}{lccc}
\hline Variables & No SHS Exposure $(\mathbf{n}=\mathbf{9 1 8})$ & SHS Exposure $(\mathbf{n}=108)$ & p-value \\
\hline Age (years \pm SD) & $68.1 \pm 10.7$ & $66.1 \pm 11.7$ & 0.033 \\
Male (\%) & 73.6 & 65.7 & 0.081 \\
Hypertension (\%) & 81.4 & 83.2 & 0.66 \\
Hyperlipidemia (\%) & 93.3 & 87.6 & 0.035 \\
Diabetes mellitus (\%) & 43.6 & 40.7 & 0.57 \\
Carotid artery disease (\%) & 24.9 & 24.3 & 0.90 \\
Stroke (\%) & 6.8 & 13.2 & 0.018 \\
Prior smoking (\%) & 61.0 & 72.4 & 0.023 \\
\hline
\end{tabular}

Values are expressed as mean \pm SD or percentage 
Table 2: Baseline Coronary Disease Factors and Revascularization Status of Non-Smokers Undergoing Enhanced External Counterpulsation

\begin{tabular}{|c|c|c|c|}
\hline Variables & No SHS Exposure $(n=918)$ & SHS Exposure $(n=108)$ & p-value \\
\hline Interval since CAD diagnosis (yrs) & $11.5 \pm 8.7$ & $10.9 \pm 8.2$ & 0.69 \\
\hline Prior myocardial infarction (\%) & 69.9 & 74.8 & 0.30 \\
\hline Heart failure (\%) & 24.5 & 26.4 & 0.66 \\
\hline Ischemic cardiomyopathy (\%) & 35.2 & 41.1 & 0.23 \\
\hline Left ventricular ejection fraction (\%) & $47.3 \pm 14.4$ & $45.4 \pm 14.7$ & 0.25 \\
\hline Prior $\mathrm{PCl}$ or $\mathrm{CABG}(\%)$ & 90.4 & 85.2 & 0.091 \\
\hline Angina episodes/week & $11.8 \pm 15.5$ & $13.0 \pm 14.2$ & 0.50 \\
\hline Angina class & & & 0.16 \\
\hline i & 2.6 & 1.9 & \\
\hline ॥ & 5.1 & 0.9 & \\
\hline III & 68.3 & 70.4 & \\
\hline IV & 24.0 & 26.9 & \\
\hline
\end{tabular}

Values are expressed as mean \pm SD or percentage

The agents and pathways responsible for these functional changes of endothelial function have not yet been completely elucidated, but they may be related, at least in part, to the inactivation of nitric oxide (NO) [17]. Animal studies have suggested that passive smoking reduces the activity of endothelial NO synthase [possibly due to the action of carbon monoxide (CO)] [32] and the endothelial arginine content [33]. In accordance with these results, it was shown that L-arginine supplementation prevented endothelial dysfunction induced by SHS in rabbits [32] and reduced the infarct size in SHS-exposed rats [34].

EECP has been shown to increase c-GMP production, which promotes vascular smooth muscle tone and improves arterial function [35]. EECP also progressively increased plasma nitric oxide levels in patients who received 1-hour daily treatments over 6 weeks by $62 \%$ compared to baseline improving endothelial function [36]. Therefore, passive smoking could attenuate the vas- cular effects of EECP by preventing the release of nitric oxide induced by the shear forces generated by EECP.

A limitation of this analysis was the assessment of SHS exposure. By defining SHS exposure as only house-hold exposure, we may have underestimated the proportion of subjects with occupational SHS. However, the vast majority of patients undergoing EECP have severe angina, and are not employed outside the home. Self-reporting of the SHS status may be a limitation. There may be other unmeasured confounding variables, such as obesity, poor diet, and physical inactivity, which may be associated with SHS. Our database was not able to capture these potential confounding variables. The IEPR-2 Registry was designed as a cohort study of patients undergoing EECP and provides a rich data set for exploration. As with many analyses of the Registry data, the SHS hypothesis was not pre-specified; this should be kept in mind in the interpretation of the findings.

Table 3: Clinical Outcomes after Enhanced External Counterpulsation of Non-Smokers Undergoing Enhanced External Counterpulsation

\begin{tabular}{|c|c|c|c|}
\hline Variables & No SHS Exposure $(n=918)$ & SHS Exposure $(n=108)$ & p-value \\
\hline Death (\%) & 0.4 & 1.9 & 0.12 \\
\hline Myocardial infarction (\%) & 1.4 & 1.9 & 0.67 \\
\hline Unstable angina (\%) & 2.6 & 8.3 & 0.0014 \\
\hline Heart failure exacerbation (\%) & 1.4 & 2.8 & 0.28 \\
\hline Coronary bypass surgery (\%) & 0.3 & 0.0 & 0.55 \\
\hline Percutaneous coronary intervention (\%) & I.I & 1.9 & 0.37 \\
\hline MACE (Death/MI/CABG/PCI) (\%) & 2.8 & 5.6 & 0.12 \\
\hline Anginal status (\%) & & & 0.044 \\
\hline No angina & 16.3 & 17.9 & \\
\hline Class I & 24.2 & 16.0 & \\
\hline Class II & 37.0 & 31.1 & \\
\hline Class III & 17.3 & 23.6 & \\
\hline Class IV & 5.3 & 11.3 & \\
\hline Angina decreased $\geq I$ class & 79.2 & 67.9 & 0.0082 \\
\hline
\end{tabular}

Values are expressed as mean \pm SD or percentage 


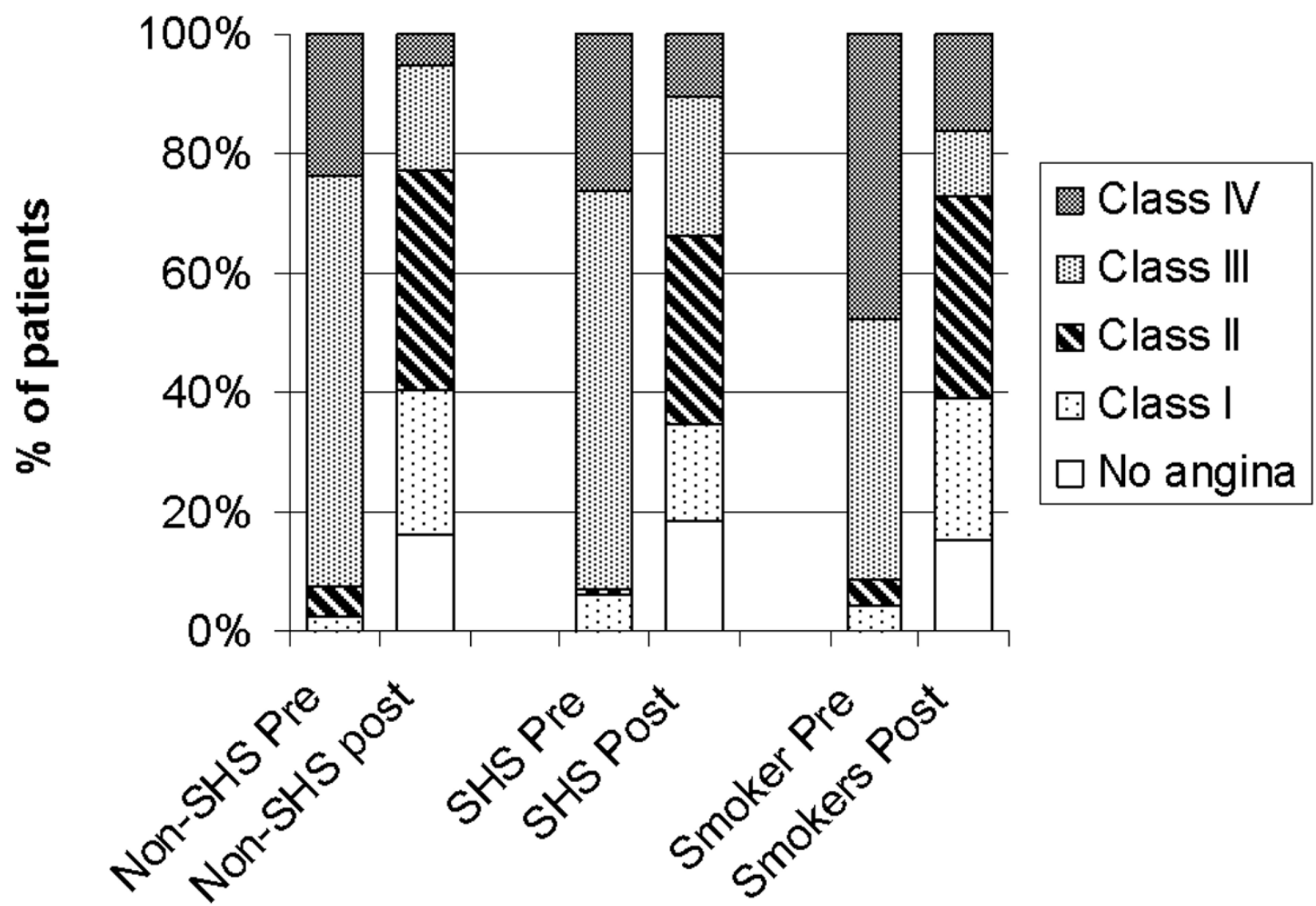

Figure I

Change in angina class from pre- to post-enhanced external counterpulsation (EECP) treatment for nonsmokers without $(n=918)$ and with $(n=108)$ second-hand smoke exposure $($ SHS $)$, and current smokers $(n=$ 363).

\section{Conclusion}

In conclusion, SHS may reduce the anti-anginal effects of EECP among non-smokers. This reduced success rate of EECP in SHS non-smokers is comparable to that seen in current cigarette smokers. These findings are consistent with studies showing that SHS exposure reduces nitric oxide production, which is an important mechanism for the clinical benefit seen with EECP.

\section{Abbreviations}

ARIC: Atherosclerosis Risk in Communities; CABG: Coronary artery bypass graft surgery; CCSC: Canadian Cardiovascular Society Classification; CO: Carbon Monoxide; CVD: Cardiovascular disease; EECP: Enhanced external counterpulsation; IEPR-II: Second International EECP Patient Registry; MACE: Major adverse cardiovascular events; NO: Nitric oxide; SHS: second-hand smoke

\section{Competing interests}

The IEPR-2 is sponsored by Vasomedical, Inc., Westbury, NY. Drs. Michaels, Kennard, and Kelsey have performed consulting for Vasomedical Inc., the manufacturer of EECP. Dr. Michaels has also participated on the speaker's bureau for Vasomedical Inc.

\section{Authors' contributions}

SE drafted the manuscript. EK, SF, and AM conceived of the study, and participated in its design and coordination and helped to draft the manuscript. All authors read and approved the final manuscript.

\section{Acknowledgements}

The IEPR-2 investigators include: 
Table 4: List of IEPR-2 investigators

\begin{tabular}{|c|c|c|c|}
\hline Site Name & Location & Investigator Name & Coordinator Name \\
\hline Advanced Heart Care & Paris, TX, United States & Jeffrey R. Gladden, MD & Diane James \\
\hline Associates in Cardiovascular Medicine & Westerville, $\mathrm{OH}$, United States & Andrew P. Klaus, MD & Brett Elliott, BS \\
\hline $\begin{array}{l}\text { Avera McKennan Hospital - Cardiovascular/ } \\
\text { Stress }\end{array}$ & Sioux Falls, SD, United States & Kevin Vaska, MD & Carol Scholten, RN \\
\hline Borgess Health \& Fitness Center & Kalamazoo, MI, United States & Alice Williams, DO & Julie Johnson \\
\hline Cardiology Consultants Ltd. & Belleville, IL, United States & Atal S. Shar, MD & Donna Mann, RN \\
\hline Cardiology Consultants PC & Albany, GA, United States & Steven C. Wolinsky, DO & Kimberly Bryan, LPN \\
\hline Cardiovascular Research Institute, Inc. & Columbus, $\mathrm{OH}$, United States & Bruce Fleishman, MD & Karen Manzo, RN \\
\hline Cardiovascular Specialists & Sandwich, MA, United States & Bruce Levy, MD & Mary Cassidy \\
\hline Central Arkansas Cardiology & N. Little Rock, AR, United States & Charles Caldwell, MD & Carrie Limberg, LPN \\
\hline Central Baptist Hospital & Lexington, $\mathrm{KY}$, United States & Pam Gage, RN & Nanette Abrams, RN \\
\hline Christ Hospital and Medical Center & Oak Lawn, IL, United States & Marc Silver, MD & Carol Pisano, RN \\
\hline Cleveland Clinic Foundation & Cleveland, $\mathrm{OH}$, United States & Stephen Ellis, MD & Jeanette Mitchell, RN \\
\hline Consultants in Cardiovascular Disease & Erie, PA, United States & William L. Mecca, MD & Monica Chase \\
\hline Creighton University Cardiac Center & Omaha, NE, United States & Paul Biddle, MD & Megan McCarthy \\
\hline ECP Heart center & Las Vegas, NV, United States & Blaine Purcell, MD & Ambar Faridi \\
\hline Edgardo Bermudez, MD & Ponce, PR, United States & Edgardo Bermudez, MD & Arlene Rivera \\
\hline EECP Center of Pittsburgh & Pittsburgh, PA, United States & Thomas Pinto, MD & Louanne Tempich, LPN \\
\hline EECP of Nassau & Valley Stream, NY, United States & Edward T. Davison, MD & Mary Getz, RN \\
\hline Elliot Hospital & Manchester, NH, United States & Robert Lavery, MD, FACC & Diane Carrier, RN \\
\hline Granite Medical Group & Quincy, MA, United States & Alan Berrick, MD & Barbara Brangiforte, LPN \\
\hline Griffin Hospital & Derby, CT, United States & Kenneth V. Schwartz, MD & Judy Grenon, RN \\
\hline Heart Centers of America, LLC & Portland, OR, United States & Ronald Schutz, MD & Ardys Hawkins, RN \\
\hline Hennepin County Medical Center & Minneapolis, MN, United States & Brad Bart, MD & Melissa Borell \\
\hline Indiana Heart Associates, PC & Indianapolis, IN, United States & Don Zipperman, MD & Shawna Toombs, EMT \\
\hline Jackson Purchase Medical Center & Mayfield, KY, United States & Tyrone Daniels, MD & Regina Williams, RRT \\
\hline JFK Medical Center & Atlantis, FL, United States & Norman Erenrich, MD & Angelica Patten, RN \\
\hline Knoxville Cardiovascular Group & Knoxville, TN, United States & Stuart Bresee, MD & Teresa Boling \\
\hline Long Island Heart Associates & Mineola, NY, United States & Steven Zeldis, MD & Robert J. Mullan \\
\hline Mayo Clinic, St. Mary's Hospital & Rochester, MN, United States & Gregory Barsness, MD & Linda Tesmer, RN \\
\hline Medical Institute of New Jersey & Cedar Knolls, NJ, United States & Leonard Moss, MD & Ellen Pateman, RN \\
\hline Medicor Cardiology & Bridgewater, NJ, United States & Kenneth Sternberge, MD & Luz Vanegas, LPN \\
\hline Mercy Hospital Medical Center & Des Moines, IA, United States & William J. Wickemeyer, MD & Donna Gideon \\
\hline Minneapolis Heart Institute Foundation & Minneapolis, MN, United States & Timothy Henry, MD & Terri Streufert, RN \\
\hline Missouri Heart Center & Columbia, MO, United States & James Elliott, MD & Jeanette Quick, RN \\
\hline Moffitt Heart \& Vascular Group & Wormleysburg, PA, United States & Jeffrey Mandak, MD & Anita Todd, RN \\
\hline North Suburban Cardiology Group, Ltd. & Arlington Heights, IL, United States & Edward Pinsel, M.D. & Laura Clemens, RN \\
\hline Northwest Ohio Cardiology Consultants & Toledo, $\mathrm{OH}$, United States & Todd L. Monroe, MD & Diane Philip, RN \\
\hline Oregon Cardiology & Eugene, OR, United States & Jay Chappell, MD & Christi Flood \\
\hline Our Lady of Lourdes Medical Center & Camden, NJ, United States & Jan R. Weber, M.D. & Cheryl Marks, RN \\
\hline Scripps Center for Integrative Medicine & La Jolla, CA, United States & Erminia Guarneri, M.D. & Eva Stuart, RN \\
\hline Shady Grove Adventist Hospital Cardiac Rehab & Rockville, MD, United States & Dennis Friedman, MD & Gail Driskill, RN \\
\hline St. Lukes Hospital & Cedar Rapids, IA, United States & Michael Chandra, MD & Deb O'Neil, RN \\
\hline Staten Island Heart & Staten Island, NY, United States & James Lafferty, MD & Laura Ferrara, RN, CRN \\
\hline Stony Brook University Hospital & Stony Brook, NY, United States & William E. Lawson, MD & Denise D'Ambrosia, FNPC \\
\hline Susquehanna Cardiology Associates & Williamsport, PA, United States & Donald Nardone, MD & Gwen Hill, RN \\
\hline The Angina Center of Evansville & Evansville, IN, United States & Ralph Millsaps, MD & Joseph Winterman, RN \\
\hline The Heart Care Group, PC & Allentown, PA, United States & James A. Pantano, MD & Ruth Ann Gerchufsky \\
\hline The Heart Group & Evansville, IN, United States & Jerry Becker, MD & Lori Hunt, RN \\
\hline University of Pittsburgh Medical & Center Pittsburgh, PA, United States & Ozlem Soran, MD & Renee Litrun, CVT \\
\hline University of Virginia & Charlottesville, VA, United States & George Beller, MD & Ellen Longmoore, CNMT \\
\hline Wake Heart Associates & Raleigh, NC, United States & R. Lee Jobe, MD & Sharon Knight, RRT \\
\hline Wichita EECP Heart Center & Wichita, KS, United States & Roger Evans, MD & Linda Rae Hillier, RN \\
\hline William Beaumont Hospital & Royal Oak, MI, United States & Peter McCullough, MD & Liberty Van Eik \\
\hline Wisconsin Heart & Madison, WI, United States & John Moses, MD & Ramona Van \\
\hline York Hospital Cardiac Rehab. & York, PA, United States & Kevin McCullum, MD & Cindy Yingling, RN \\
\hline Cardiology Consultants Ltd. & Belleville, IL, United States & Atal S. Shar, MD & Donna Mann, RN. \\
\hline
\end{tabular}




\section{References}

I. Glantz SA, Parmley WW: Passive smoking and heart disease. Mechanisms and risk. JAMA 1995, 273:1047-1053.

2. Prevention. ENfSP: Smoke Free Workplaces: Improving the health and the wellbeing of people at work. Brussels: European Network for Smoking Prevention; 200l.

3. I986 Surgeon General's report: the health consequences of involuntary smoking. MMWR Morb Mortal Wkly Rep 1986 35:769-770

4. Taylor BV, Oudit GY, Kalman PG, Liu P: Clinical and pathophysiological effects of active and passive smoking on the cardiovascular system. Can J Cardiol 1998, I4:1 I29-II39.

5. Howard G, Wagenknecht LE, Burke GL, Diez-Roux A, Evans GW, McGovern P, Nieto FJ, Tell GS: Cigarette smoking and progression of atherosclerosis: The Atherosclerosis Risk in Communities (ARIC) Study. JAMA 1998, 279: I I9-I 24.

6. Steenland $\mathrm{K}$ : Passive smoking and the risk of heart disease. JAMA 1992, 267:94-99.

7. Wells AJ: Passive smoking as a cause of heart disease. J Am Coll Cardiol 1994, 24:546-554.

8. Barnoya J, Glantz SA: Secondhand smoke: the evidence of danger keeps growing. Am J Med 2004, I I 6:20 I-202.

9. Howard GTM: Why is environmental tobacco smoke more strongly associated with coronary heart disease than expected? A review of potential biases and experimental data. Environ Heath Perspect 1999, 107:853-858.

10. Report of the Scientific Committee on Tobacco and Health: Secondhand smoke: review of evidence since 1998: update of evidence of health effects of secondhand smoke. London: The Stationery Office; 2004

II. Whincup PH, Gilg JA, Emberson JR, Jarvis MJ, Feyerabend C, Bryant A, Walker M, Cook DG: Passive smoking and risk of coronary heart disease and stroke: prospective study with cotinine measurement. Bmj 2004, 329:200-205.

12. Lawson WE, Hui JC, Lang G: Treatment benefit in the enhanced external counterpulsation consortium. Cardiology 2000, 94:3I-35.

13. Fitzgerald CP, Lawson WE, Hui JC, Kennard ED, IEPR Investigators: Enhanced external counterpulsation as initial revascularization treatment for angina refractory to medical therapy. Cardiology 2003, I00:129-135.

14. Arora RR, Chou TM, Jain D, Fleishman B, Crawford L, McKiernan T, Nesto R, Ferrans CE, Keller $S$ : Effects of enhanced externa counterpulsation on health-related quality of life continue I 2 months after treatment: a substudy of the Multicenter Study of Enhanced External Counterpulsation. I Investig Med 2002, 50:25-32.

15. Fricchione GL, Jaghab K, Lawson W, Hui JC, Jandorf L, Zheng ZS, Cohn PF, Soroff H: Psychosocial effects of enhanced external counterpulsation in the angina patient. Psychosomatics 1995, 36:494-497.

16. Lawson WE, Hui JC, Soroff HS, Zheng ZS, Kayden DS, Sasvary D, Atkins $H$, Cohn PF: Efficacy of enhanced external counterpulsation in the treatment of angina pectoris. Am J Cardiol 1992 70:859-862.

17. Masuda D, Nohara R, Hirai T, Kataoka K, Chen LG, Hosokawa R, Inubushi M, Tadamura E, Fujita M, Sasayama S: Enhanced external counterpulsation improved myocardial perfusion and coronary flow reserve in patients with chronic stable angina; evaluation by (13) N-ammonia positron emission tomography. Eur Heart J 200I, 22: |45|-|458.

18. Lawson WE, Hui JC, Guo T, Burger L, Cohn PF: Prior revascularization increases the effectiveness of enhanced externa counterpulsation. Clin Cardiol 1998, 2 I:84I-844.

19. Lawson WE, Hui JC, Zheng ZS, Burgen L, Jiang L, Lillis O, Oster Z Soroff H, Cohn P: Improved exercise tolerance following enhanced external counterpulsation: cardiac or peripheral effect? Cardiology 1996, 87:27I-275.

20. Arora RR, Chou TM, Jain D, Fleishman B, Crawford L, McKiernan T, Nesto RW: The multicenter study of enhanced external counterpulsation (MUST-EECP): effect of EECP on exerciseinduced myocardial ischemia and anginal episodes. J Am Coll Cardiol 1999, 33:1833-1840.

21. Lawson WE, Hui JC, Cohn PF: Long-term prognosis of patients with angina treated with enhanced external counterpulsation: five-year follow-up study. Clin Cardiol 2000, 23:254-258.
22. Lawson WE, Hui JC, Zheng ZS, Oster Z, Katz JP, Diggs P, Burger L, Cohn CD, Soroff HS, Cohn PF: Three-year sustained benefit from enhanced external counterpulsation in chronic angina pectoris. Am J Cardiol I 995, 75:840-84I.

23. Lawson WE, Kennard ED, Hui JC, Kennard ED, IEPR Investigators: Analysis of baseline factors associated with reduction in chest pain in patients with angina pectoris treated by enhanced external counterpulsation. Am J Cardiol 2003, 92:439-44.

24. Barsness G, Feldman AM, Holmes DR Jr, Holubkov R, Kelsey SF, Kennard ED, International EECP Patient Registry Investigators: The International EECP Patient Registry (IEPR): design, methods, baseline characteristics, and acute results. Clin Cardio 200I, 24:435-442.

25. Celermajer DS, Sorensen KE, Georgakopoulos D, Bull C, Thomas O Robinson J, Deanfield JE: Cigarette smoking is associated with dose-related and potentially reversible impairment of endothelium-dependent dilation in healthy young adults. Circulation 1993, 88:2149-2155.

26. Heitzer T, Ylä-Herttuala S, Luoma J, Kurz S, Münzel T, Just H, Olschewski M, Drexler H: Cigarette smoking potentiates endothelial dysfunction of forearm resistance vessels in patients with hypercholesterolemia. Role of oxidized LDL. Circulation 1996, 93:I346-1353.

27. Zeiher AM, Schachinger V, Minners J: Long-term cigarette smoking impairs endothelium-dependent coronary arterial vasodilator function. Circulation 1995, 92: 1094-I I00.

28. Celermajer DS, Adams MR, Clarkson P, Robinson J, McCredie R Donald A, Deanfield JE: Passive smoking and impaired endothelium-dependent arterial dilatation in healthy young adults. $N$ Engl ] Med 1996, 334: I50-I54.

29. Sumida $H$, Watanabe $H$, Kugiyama K, Ohgushi M, Matsumura T, Yasue $H$ : Does passive smoking impair endothelium-dependent coronary artery dilation in women? I Am Coll Cardiol 1998, $31: 8|\mathrm{I}-8| 5$.

30. Otsuka R, Watanabe H, Hirata K, Tokai K, Muro T, Yoshiyama M, Takeuchi K, Yoshikawa J: Acute effects of passive smoking on the coronary circulation in healthy young adults. JAMA $200 \mathrm{I}$, 286:436-44I.

3I. Barnoya J, Glantz SA: Cardiovascular effects of secondhand smoke: nearly as large as smoking. Circulation 2005, I I | :2684-2698.

32. Johnson FK, Johnson RA: Carbon monoxide promotes endothelium-dependent constriction of isolated gracilis muscle arterioles. Am I Physiol Regul Integr Comp Physiol 2003, 285:R536-54I.

33. Hutchison SJ, Sievers RE, Zhu BQ, Sun YP, Stewart DJ, Parmley WW, Chatterjee K: Secondhand tobacco smoke impairs rabbit pulmonary artery endothelium-dependent relaxation. Chest 200I, I 20:2004-2012

34. Zhu B, Sun Y, Sievers RE, Shuman IL, Glantz SA, Chatterjee K, Parmley WW, Wolfe CL: L-arginine decreases infarct size in rats exposed to environmental tobacco smoke. Am Heart J 1996, 132:91-100.

35. Levenson J, Pernollet MG, lliou MC, Devynck MA, Simon A: Cyclic GMP release by acute enhanced external counterpulsation. Am J Hypertens 2006, 19:867-872.

36. Akhtar M, Wu GF, Du ZM, Zheng ZS, Michaels AD: Effect of external counterpulsation on plasma nitric oxide and endothelinI levels. Am J Cardiol 2006, 98:28-30.

\section{Pre-publication history}

The pre-publication history for this paper can be accessed here:

http://www.biomedcentral.com/1471-2261/8/23/prepub 